\title{
FOMENTO DE LA EXPRESIÓN ORAL Y EL PENSAMIENTO CRÍTICO A TRAVÉS DEL DEBATE
}

\section{DEVELOPMENT OF ORAL EXPRESSION AND CRITICAL THINKING THROUGH THE DEBATE}

\author{
Manuel Bermúdez Vázquez y Elena Casares Landauro \\ manuel.bermudez@uco.es \\ Universidad de Córdoba
}

Received: 20/07/2017Ａccepted: 04/12/2017

\begin{abstract}
This project aims to develop reflection, debate and critical thinking among students. Making the best of the structure already created with the "Aula de Debate" of the University of Cordoba, which brings together about 170 students from all areas of study of the university, the idea is to extend this experience. Academic debates involving students encourage all kinds of intellectual benefits, ranging from the orderly presentation of arguments, the development of critical thinking, the ability to dialogue to the improvement of oral presentations. If we think in the same way we speak, it is very convenient for the students to learn to speak in the best possible manner.
\end{abstract}

Keywords: critical thinking; oral expression; debate.

\section{Resumen}

Este proyecto persigue potenciar la reflexión, el debate y el pensamiento crítico entre los estudiantes. Aprovechando la estructura creada con el Aula de Debate de la Universidad de Córdoba, la idea es ampliar esta experiencia tan universitaria a cuantos más estudiantes mejor. Mediante los debates académicos en los que participan los estudiantes se fomentan todo tipo de beneficios intelectuales como la presentación ordenada de argumentos, el desarrollo del pensamiento crítico, la capacidad de diálogo y la mejora de la expresión oral. Los estudiantes tienen que afrontar presentaciones en clase, entrevistas de trabajo y exposiciones en su vida cotidiana. Si pensamos como hablamos, resulta muy conveniente que los estudiantes aprendan a hablar de la mejora manera posible y sean capaces de presentar sus ideas de una forma clara y adecuada al contexto al que se estén dirigiendo.

Palabras clave: pensamiento crítico; expresión oral; debate.

\section{INTRODUCCIÓN}

La retórica es, según Platón, "el arte de ganarse la voluntad humana a través de la palabra". Se trata de una definición escueta 
pero tremendamente gráfica. Por medio del lenguaje hablado el ser humano es capaz de cambiar las opiniones, sentimientos e incluso las acciones de aquellos que le rodean, y que en un principio partían de unos supuestos diferentes a los nuestros.

Como indica el experto Juan Mamberti en su libro Tolerancia crítica y ciudadanía activa, el debate es un proceso de aprendizaje en el que los resultados deben ser evaluados en función de dos premisas básicas: el incremento del saber y el aumento de la comprensión del tema debatido. ${ }^{1}$ La valoración en términos de ganadores y perdedores queda fuera de nuestro interés. En un debate se contribuye a la construcción del conocimiento de manera colectiva, en equipo y todos los participantes son elementos fundamentales del mismo. Un debate sirve, entre otras mil cosas, para cuestionar el estado de las cosas que, en muchas ocasiones, parecen estar más allá de la crítica.

La comunicación parte de la base de que la forma en que se expresan las ideas es tan importante como la esencia que encierran. No basta con expresar en voz alta las ideas, sino que la forma en que tiene lugar esta expresión determina el efecto que las palabras tienen en aquellos que las escuchan. Se trata de que el mensaje que recibe el receptor coincida exactamente con lo que quiere expresar el emisor, y que además tenga la fuerza suficiente como para que sea aceptado como verdadero. Si a la oratoria le añadimos el desarrollo del pensamiento crítico, una de las parcelas fundamentales de la filosofía contemporánea, obtendríamos como resultado un grupo de personas capaces de analizar las ideas, comprobar su veracidad y expresar sus propias posiciones. Esto, que puede parecer algo evidente, no es tan frecuente ni tan siquiera en las aulas universitarias, uno de los lugares donde más falta haría. El debate, que fomenta la capacidad de diálogo, el intercambio de ideas y la comprensión del otro, es una pieza capital de todo sistema democrático y su fomento en la universidad no puede ser más oportuno.

La idea que hay detrás de este proyecto de innovación es incorporar a las aulas universitarias esta actividad de diálogo, reflexión y análisis que es el debate. Mediante una aproximación multidisciplinar, alumnos de distintas titulaciones y distintas facultades tendrán la posibilidad de aprender a expresarse mejor y

${ }^{1}$ Juan Mamberti et alii, Tolerancia crítica y cindadanía activa, IdebatePress, Nueva York, 2010, p.11. 
con más tino, con mayor precisión y orden, respetando las opiniones y argumentos de los demás y viendo en el otro a una persona que piensa y siente, fomentando de este modo la comprensión y el diálogo. Terry Eagleton, profesor británico de literatura, definió una vez la maldad como "la ausencia total de empatía". Si la empatía consiste en entender la postura y las ideas del otro, en participar de forma activa en el proceso del diálogo, en ponerse en la piel del otro, entonces esta actividad que proponemos es justamente eso, de modo que, fomentándola, estaríamos contribuyendo a combatir los efectos perniciosos de la instrumentalización y la cosificación, estaríamos haciendo mejores a los estudiantes.

\section{OBJETIVOS}

Entre los objetivos que proponemos está el fomento de la capacidad crítica, la expresión oral, el desarrollo ordenado de ideas, el análisis profundo de diversos temas, la capacidad de defender con la palabra una idea o una opinión, el estudio y la investigación de cuestiones académicas y temas de actualidad, el fomento del trabajo en equipo, el respeto a la opinión de los demás, la distinción entre argumentos y opiniones y, en general, la mejora sustancial del rendimiento intelectual de los alumnos. La meta final de este proyecto es que sus participantes puedan afrontar en las mejores condiciones las circunstancias que la vida trae en las aulas y tras la universidad. Recientemente, algunos directivos que ofrecen la oportunidad a los alumnos de la UCO de realizar las prácticas en sus empresas se quejaban de que, precisamente, la mayoría de los estudiantes que tenían que afrontar una entrevista para obtener el puesto de becario lo hacían de forma precaria. Así, uno de los objetivos que perseguimos es que los alumnos mejoren en su capacidad de expresarse, tanto en público como privadamente. Un discurso ordenado suele llevar parejo una mente ordenada y, en estos tiempos de mensajes fugaces y superficiales, es cuando más hay que apostar por el fomento del análisis del discurso y la expresión oral clara y razonada.

$\mathrm{Si}$ nos ponemos a pensar por qué defendemos alguna cosa, generalmente, se nos vienen a la cabeza unos pocos argumentos quizá poco reflexionados y superficiales. Con la labor que pretendemos llevar a cabo mediante este proyecto de innovación educativa los estudiantes aprenderán herramientas con las que evitar estos problemas. Tomarán conciencia de la importancia de aportar argumentos de una manera buena y bella para explicar la propia 
postura, de temas tanto académicos como de actualidad. Además, en el camino, se adquirirán instrumentos para comprender un poco mejor la postura del otro, para respetar sus opiniones, para permitir que la palabra tenga un tránsito fluido y se produzca, justamente, el diálogo. Con este proyecto no solo se pretende enseñar a hablar más razonadamente y con mejor expresión, se intenta también fomentar ideas de fuerte componente democrático como la tolerancia y la empatía. Estaríamos fomentando la formación de mejores ciudadanos, conscientes tanto de sus derechos como de sus obligaciones.

Objetivos concretos:

- Mejorar la competencia lingǘstica del alumno y su capacidad de razonar lógicamente.

-Potenciar la autonomía personal y de pensamiento.

-Desarrollar la tolerancia y el respeto ante las opiniones ajenas, favoreciendo la empatía.

- Habilitar espacios de discusión intelectual dentro de los límites de la tolerancia, la valoración del contrario, la convivencia y la cortesía.

- Promover una actitud crítica e independiente ante los distintos acontecimientos sociales y culturales, cotejando distintos datos y reconociendo procesos manipulativos, falacias y demagogias.

-Incitar la curiosidad en el alumno para profundizar en las causas y motivos de los distintos acontecimientos.

-Hacer patente al alumno que es posible aprender de forma lúdica. -Enriquecimiento del horizonte cultural del alumno.

\section{METODOLOGÍA}

Uno de los temores que nos asaltaron a la hora de explicar la metodología que proponemos para desarrollar este proyecto es que buscando concisión corramos el riesgo de caer en el laconismo y buscando precisión podamos caer en la prolijidad.

Entre las bazas que considero que están del lado de esta propuesta está la aplicación que de la misma hemos ido desarrollando desde el curso 2011-2012. En el marco del Aula de Debate de la UCO hemos logrado reunir a un grupo de alumnos (aproximadamente unos 150 entre las distintas facultades) motivados e interesados por participar en esta actividad de debate y de fomento de la expresión oral y el pensamiento crítico. Se han reservado aulas fuera del horario lectivo diversos días de cada semana y ahí hemos venido practicando las actividades típicas de un grupo de debate y pensamiento crítico. Las actividades que hemos llevado a cabo han 
sido considerables. Se diseñaron una serie de ejercicios que los estudiantes llevaron a cabo que consistían en aprender a discernir entre afirmaciones fácticas y juicios de valor, se trabajó sobre la diferencia entre opiniones y argumentos, se desarrolló la capacidad de pensamiento deductivo con ejercicios paulatinamente más difíciles, desde silogismos simples hasta complejas líneas de pensamiento y discursos políticos. Estos ejercicios, de elaboración propia, los hemos colgado en un blog dedicado al aula de debate y que se ha mostrado una herramienta muy potente a la hora de facilitar el acceso a los estudiantes a estos materiales (http://manuelbermudezvazquez.wordpress.com/). Hemos diseñado dos blogs distintos (http://www.debatefilosofia.blogspot.com.es/) (http://clubdebateuc o.blogspot.com.es/?srt=1332499559244\&refurl) dirigidos a todos los estudiantes de la UCO. La web principal es la del Aula de Debate www.uco.es/auladebate.

Una de las consecuencias directas de toda esta actividad ha sido que algunos equipos de debate organizados a través de estas clases fueron invitados participar en debates en otras universidades españolas.

El Aula de Debate ha organizado durante los últimos tres años varios cursos de competencias culturales dirigidos a los alumnos interesados.

Con este proyecto pretendemos contribuir a la mejora sustancial de la capacidad intelectual de nuestros alumnos mediante el desarrollo de la expresión oral y el fomento del pensamiento crítico, quizá hoy en día más necesario que nunca. La experiencia llevada a cabo hasta ahora demuestra que con pocos medios se pueden lograr grandes avances. Consideramos que es conveniente que la Universidad de Córdoba apoye con fuerza esta idea, ya que no trae más que beneficios para todos, para los alumnos con el fomento y la dotación de nuevas y mejores herramientas para afrontar la dura realidad profesional, para la universidad por la calidad intelectual que se asegurará que obtendrán sus alumnos y para los profesores porque tendremos la oportunidad de disponer de un foro donde desarrollar este tipo de proyectos innovadores. En suma, este es un proyecto modesto pero de ilimitadas posibilidades.

\section{DESCRIPCIÓN}

Los ejercicios que hemos creado para fomentar el debate tienen una razón de ser obvia: el aprendizaje de los métodos más eficaces 
para incorporar el pensamiento crítico en las actividades orales de los estudiantes. Entre otros tenemos:

-a) Ejercicio de improvisación argumentativa. Se distribuye aleatoriamente una serie de frases entre los estudiantes que tienen que presentarse y luego, por primera vez, leer en voz alta el contenido y argumentar al menos durante dos minutos por qué defienden lo que acaban de leer.

-b) Ejercicio de argumentación. El dramaturgo polaco Slawomir Mrozek escribió en 1961 una obra de teatro en la que tres náufragos van a la deriva en una balsa en alta mar y empiezan a sentir un hambre feroz y deciden a la desesperada que uno de los tres deberá sacrificarse y servir de alimento a los otros dos. Pero, ¿cuál de los tres? Como son personas civilizadas y razonables, cada uno tratará de convencer a los otros dos de que no es la víctima apropiada para tal sacrificio. ¿Quién será el más persuasivo de los tres? ¿Quién salvará su vida gracias a la retórica?

Procedimiento:

Cada participante toma un perfil para sí y lo estudia. Analiza también el perfil de los otros dos adversarios, buscando sus puntos débiles.

En la primera ronda ( 2 minutos), cada uno habla de sus propias cualidades y de las razones por las que debería salvarse del sacrificio. Deberá ser imaginativo, lógico y persuasivo. Debe ceñirse al papel, pero puede inventar una cualidad o circunstancia no escrita (sólo una) que le dé más peso a su personaje.

En las siguientes tres rondas (estrictamente, 1 minuto cada uno), deben atacar los argumentos de sus adversarios y reforzar los suyos, contestando a las críticas de los otros.

Finalmente, el jurado rellena la ficha de valoración y emite su veredicto, explicando lo que han hecho bien y lo que deberían mejorar cada uno.

-c) Ejercicio de razonamiento y contraargumentación: comprar y vender objetos. Objetivos: improvisar argumentos coherentes, bien razonados y presentados de forma original y atractiva. Mejorar nuestras habilidades de comunicación y persuasión. Defender una postura bajo presión sin dar su brazo a torcer.

Procedimiento: busca en el trastero de tu casa algún objeto inservible, como un juguete viejo o un utensilio estropeado. Tu objetivo es vendérselo a tu oponente y que él no te convenza de que le compres el suyo (por turnos). Si formáis grupos de cuatro, dos 
pueden hacer de jueces y rellenar la rúbrica de valoración, mientras los otros dos actúan.

Tarea: $1^{\circ}$ ) Antes de empezar, imagina usos alternativos para ese objeto inútil que lo hagan de nuevo atractivo o valioso. $2^{\circ}$ ) Empieza preguntando a tu oponente sus aficiones, si tiene hijos, etc. para intentar "acoplarle" tu producto. $3^{\circ}$ ) Supera las resistencias de tu oponente reforzando tus argumentos y buscando otros nuevos.

-d) Ejercicio de analogías. Podemos pensar que el razonamiento analógico no tiene una gran fuerza probatoria en un debate. De hecho, lo que hacemos en una analogía es simplemente mostrar el parecido entre un caso particular y otro caso particular, lo cual no nos puede llevar a extraer conclusiones demasiado generales y contundentes, sino más bien probabilísticas. Sin embargo, el razonamiento analógico es de los más potentes y usados por el ser humano. Una buena analogía clarifica e ilustra el pensamiento más abstracto y le da forma definida a nuestras intuiciones con una gran fuerza evocadora. ${ }^{2}$

\section{RESULTADOS OBTENIDOS}

Los resultados que esperamos obtener con este proyecto son fáciles de evaluar. Los alumnos que participan en las actividades del Aula de Debate demuestran empíricamente una capacidad mayor a la hora de organizar su pensamiento, expresar ordenadamente las ideas, ordenar jerárquicamente las razones aportadas ante un tema. Cualquier propuesta oral que les planteen la resolverán de la manera más aguda y atinada. No todo los días se ve a un universitario de unos 20 años siendo capaz de razonar, argumentar y presentar correctamente un contenido. La disponibilidad de uso queda más allá de lo medible, porque gracias a este proyecto hemos contribuido a que alumnos de nuestra universidad mejoren sus capacidades de una forma exponencial. Todos y cada uno de ellos se van a beneficiar en su futuro de lo aprendido mediante nuestro proyecto. Cada vez que tengan una entrevista de trabajo, cada vez que tenga que explicar algo, que tengan que discutir o que tengan que escuchar a otra persona, estarán utilizando las competencias que les hemos ayudado a adquirir.

${ }^{2}$ Mario Carretero y Mikel Asensio: Psicología del Pensamiento, Alianza Editorial, p. 248. 


\section{UTILIDAD/ANÁLISIS}

En el año 2012, los principales especialista del ámbito laboral en el mundo occidental se reunieron en la London School of Economics, una de las más prestigiosas universidades del mundo y llegaron al a conclusión de que los trabajadores del siglo XXI van a necesitar tres capacidades fundamentales: 1) Dominio básico de matemáticas y estadística. 2) Conocimiento básico de inglés. 3) Ser capaces de defender un argumento.

Es, precisamente, este último apartado el que está menos trabajado en todo el ámbito universitario europeo y el que tenemos que recuperar y trabajar. Los estudiantes necesitan aprenderr a ser capaces de defender un argumento, tienen que saber enfrentarse a la vida con la palabra, con las ideas, sabiendo bien cómo organizar sus intervenciones, controlando el tiempo del que disponen y actuando en consecuencia.

Las actividades que proponemos a través de este formato de debate son tremendamente útiles no solo para las necesidades académicas de los estudiantes, sino para sus vidas. La utilidad del debate es evidente. No hay más que constatarlo conociendo a las personas que lo practican.

\section{CONCLUSIONES/DISCUSIÓN}

El proyecto que hemos ejecutado ha sido una herramienta formidable para la formación de todos los estudiantes que lo han disfrutado. La comunidad del debate es cada vez más numerosa y comprometida. No podemos sino congratularnos de haber conseguido, en estos 5 años de existencia del Aula de Debate, unos logros tan formidables. Las vidas y las carreras profesionales de decenas de personas han visto potenciadas sus expectativas gracias a estas actividades que son tan formativas y tan valiosas.

La apuesta por el debate como herramienta educativa y formativa es una gran idea, pues a través de él se consigue trabajar la argumentación, el razonamiento, la expresión oral, el pensamiento lógico, el pensamiento crítico, la gestión del tiempo, la adecuación del discurso al nivel de auditorio, el diálogo, la escucha del otro, etcétera, etcétera. Hay pocas actividades que, de una forma tan lúdica, consigan tantos objetivos. Por eso debemos llegar a la conclusión de que esta iniciativa es importante para el ámbito universitario. 
BIBLIOGRAFÍA

Bermúdez VÁzQuez, M. "La defensa oral del Trabajo Fin de Grado", Guía práctica para el trabajo de fin de grado en educación, Barcelona, 2017, p. 139-154.

Bermúdez VÁzQuez, M. "Análisis del discurso político contemporáneo: el camino de la retórica a la política", Comunicación y pensamiento. Comunicacracia y desarrollo social, Sevilla, 2016, p. 139-154.

MAMBERTI, J. et alii, Tolerancia crítica y ciudadanía activa, Nueva York, 2010.

Platón, Gorgias, Madrid, 1987.

VAllejo, F., Logoi, México D. F., 2011. 